\title{
About phases dependence in a switched reluctance generator
}

\author{
Dias, R. J., Coelho, A. and Fleury, A. \\ Departamento de Engenharia da Universidade Católica de Goiás (UCG) \\ Av. Universitária, 1440, Área III, Bloco G, Sala 108, CEP 74605-010, Goiânia-GO, Brasil \\ E-mails:renatojayme@hotmail.com, coelho.ee@gmail.com, afleury@terra.com.br
}

\begin{abstract}
This paper analyses and discusses the phase's dependence of the switched reluctance generator - SRG. A 6x4 SRG prototype was assembling for tests. Each one of this SRG phases can be connected and disconnected when needed. A reduced switches count converter that was use to drive the SRG. Experimental results showed changes in the characteristics wave forms of two operational phases when the third phase is disconnected. At a first sight, it was an unexpected result [1], [2]. Although many tests were conduced confirming the first result. Therefore, it should be say that for the prototype tested under the conduced testing conditions each phase behavior depends in the other phases behave. Remarkable changes in the waveforms those are present here. They show that there is not independence between the phases but a truly strong dependence among them.
\end{abstract}

\section{Key words}

Switched reluctance generator (SRG), reduced switches count, phase's dependence, phase voltage, mutual inductance.

\section{Nomenclature}

$\begin{array}{ll}v & \text { Phase voltage } \\ i & \text { Phase current } \\ R & \text { Phase resistance } \\ L & \text { Phase inductance } \\ \omega & \text { Angular speed } \\ \lambda & \text { Flux linkage } \\ \theta & \text { Rotor angular position } \\ t & \text { Time } \\ n & \text { Number of phase } \\ \Re & \text { Reluctance } \\ e & \text { Back electromotive force } \\ L_{\max } & \text { Maximum inductance } \\ L_{\min } & \text { Minimum inductance }\end{array}$

\section{Introduction}

The principle of operation of the switched reluctance machine is knew since the beginning of the electrical machines development. Soon the driving of these machines proved to be somewhat complex. The advances on power electronics and micro processing in the last decade renewed the expectancies. In fact, modern power electronic converters associated with micro processed control hardware have brought competitiveness to SRG driven systems, allowing their efficient and reliable use. Therefore, the SRG sprouted again in a new scene.

This paper focuses the SRG. In these machines phase coils are concentrated windings in the stator poles. There are no windings in its rotor. The doubly salient poles structure is a characteristic inherent to these machines. Therefore, there is minimal thermal loss in the rotor. A SRG is easy to construct and to maintain. Its commonly quoted advantages are the absence of permanent magnets, a low manufacturing costs, reliability, robustness and efficiency. The operational speed range is very wide.

Though these advantages have already been confirming, some aspects of these machines must be mentioning here: there is a strong magnetic discontinuity providing current, voltage and torque ripples that should be properly controlling. The power electronics requirements to control a SRG are sometimes quoting as a disadvantage of this kind of machine. Furthermore, they are a little noisy.

Due to its advantages, SRG are considering as a special electrical generator for wind power.

Fig. 1 shows that a switched reluctance machine works as a motor or as a generator depending on the firing angles [4]. Albeit the device is the same, the Switched Reluctance Generator (SRG) is different from the Switched Reluctance Motor (SRM) in some specific and essential aspects: the SRG has a mechanical input the torque at its shaft - and an electrical input - the excitation power. Its output is the electrical power supplied to the load. This machine presents two different electric circuit configurations per phase: one for its excitation and another for the generation period. The SRM has an electrical input, a mechanical output and just one main electric circuit per phase. 


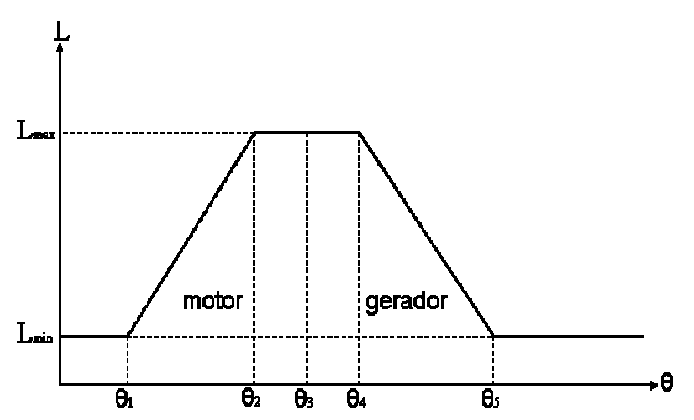

Fig. 1 - Motor and generator modes for a Switched Reluctance Machine.

The electrical and magnetic independence of the phases are frequently quoting as advantage of the Switched Reluctance Motors. This article analyses and discusses this aspect at a SRG. It was revealed that there is dependence among the SRG phases. Experimental results those are present to proof this point.

\section{Mathematical model}

A SRG is a DC machine. Its phase's excitation requires a DC source. A converter is used to drive the device. Fig. 2 shows the schema of the converter used to get the experimental results presented here.

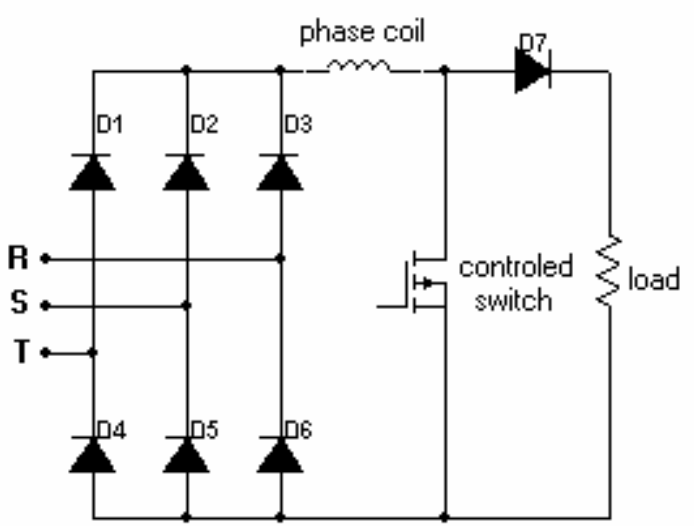

Fig. 2 - Electrical scheme of the converter topology used.

The phase winding voltage that is given by:

$$
v=R i+\frac{\partial \lambda}{\partial t}
$$

As $\lambda$ is: $\quad \lambda=L i$

$$
\partial \lambda=\frac{L d i}{d t}+i \frac{d L}{d \theta} \frac{d \theta}{d t}
$$

Therefore: $v=R i+L \frac{d i}{d t}+i \omega \frac{d L}{d \theta}$

Where $\frac{d \theta}{d t}=\omega$

The first term of the second member of the equation (4) is the voltage fall over the resistance of the coil. The second term is the inductive voltage fall and the third one is the back electromotive force - EMF is give by:

$$
e=i \cdot \omega \cdot \frac{\partial L}{\partial \theta}
$$

The stator winding is feeding in DC. As $\omega$ and $i$ are both positive, the sign of $e$ is the same as that of $\frac{\partial L}{\partial \theta}$. From (6) it can be seen that when $\frac{\partial L}{\partial \theta}>0$ the back electromotive force is positive. In this case, electric power is converting to mechanical power and the machine works as a motor. However, when $\frac{\partial L}{\partial \theta}<0$ the back electromotive force is negative and it increases the current converting mechanical power into electrical power [4].

The dynamic mechanical equation for the SRG is giving by (3). It is to be noting that the electromagnetic torque $C_{\text {emag }}$ comes as a negative quantity, i. e., acting against the rotor mechanical speed.

$$
C_{m}+C_{\text {emag }}-J \frac{d \omega}{d t}-D . \omega=0
$$

The co-energy of a phase of this machine is given by:

$$
W^{c o}=\int_{0}^{i} \lambda d i
$$

And the corresponding electromagnetic torque for an $n$ phase SRG is given by:

$$
C_{\text {emag }}=\sum_{x=1}^{n} \frac{\partial W_{x}^{c o}}{\partial \theta}
$$

The mathematical model of the SRG regarding a three-phase prototype is show below:

$$
\left[\begin{array}{c}
v_{a} \\
v_{b} \\
v_{c} \\
C_{m} \\
0
\end{array}\right]=\left[\begin{array}{ccccc}
R_{a} & 0 & 0 & 0 & 0 \\
0 & R_{b} & 0 & 0 & 0 \\
0 & 0 & R_{c} & 0 & 0 \\
-r_{a} / i_{a} & -r_{b} / i_{b} & -r_{c} / i_{c} & D & 0 \\
0 & 0 & 0 & -1 & 0
\end{array}\right] \cdot\left[\begin{array}{c}
i_{a} \\
i_{b} \\
i_{c} \\
\omega \\
\theta
\end{array}\right]+
$$

$$
+\left[\begin{array}{ccccc}
L_{a} & 0 & 0 & 0 & i_{a} \frac{\partial L_{a}}{\partial \theta} \\
0 & L_{b} & 0 & 0 & i_{b} \frac{\partial L_{b}}{\partial \theta} \\
0 & 0 & L_{c} & 0 & i_{a} \frac{\partial L_{c}}{\partial \theta} \\
0 & 0 & 0 & J & 0 \\
0 & 0 & 0 & 0 & 1
\end{array}\right] \cdot\left[\begin{array}{c}
\dot{i}_{a} \\
\dot{i}_{b} \\
\dot{i}_{c} \\
\dot{\omega} \\
\dot{\theta}
\end{array}\right]
$$

Where:

$r_{a}=\frac{\partial W_{a}^{c o}}{\partial \theta} ; r_{b}=\frac{\partial W_{b}^{c o}}{\partial \theta}$ and $r_{c}=\frac{\partial W_{c}^{c o}}{\partial \theta}$ 
If the matrices above are designating $[V],[R],[I],[L]$ and $[\dot{I}]$ exactly in the order they appear in (12), the matrix of states for the SRG has the form:

$$
\dot{I I}]=[L]^{-1}[V]-[L]^{-1}[R][I]
$$

\section{Simulation}

The simulations were do using data from a small prototype of SRG. Its parameters and dimensions are giving in Table I.

TABLE I. - Characteristic of SRG used

\begin{tabular}{|c|c|c|}
\hline Parameter & Value & Units \\
\hline Stator Diameter & 140 & $\mathrm{~mm}$ \\
\hline Rotor Diameter & 70 & $\mathrm{~mm}$ \\
\hline Stack Length & 107 & $\mathrm{~mm}$ \\
\hline Air Gap Length & 0.4 & $\mathrm{~mm}$ \\
\hline Stator Teeth Width & 19 & $m m$ \\
\hline Rotor Teeth Width & 20 & $\mathrm{~mm}$ \\
\hline Stator Slot & 22.5 & $\mathrm{~mm}$ \\
\hline Rotor Slot & 11.7 & $\mathrm{~mm}$ \\
\hline Stator Yoke & 12 & $\mathrm{~mm}$ \\
\hline Rotor Yoke & 12.4 & $\mathrm{~mm}$ \\
\hline Shaft Diameter & 22 & $\mathrm{~mm}$ \\
\hline $\begin{array}{c}\text { Number of turns per } \\
\text { phase }\end{array}$ & 50 & Turns/phase \\
\hline Inertia & 0.0028 & Kg.m ${ }^{2}$ \\
\hline Coefficient of Friction & 0.026 & N.m.s \\
\hline $\begin{array}{c}\text { Inductance } \\
\text { (Aligned Position) }\end{array}$ & 36 & $m H$ \\
\hline Shaft Diameter & 22 & $\mathrm{~mm}$ \\
\hline $\begin{array}{l}\text { Number of turns per } \\
\text { phase }\end{array}$ & 50 & Turns/phase \\
\hline Inertia & 0.0028 & Kg. $m^{2}$ \\
\hline Coefficient of Friction & 0.026 & N.m.s \\
\hline $\begin{array}{c}\text { Inductance } \\
\text { (Aligned Position) }\end{array}$ & 36 & $m H$ \\
\hline Shaft Diameter & 22 & $\mathrm{~mm}$ \\
\hline $\begin{array}{c}\text { Number of turns per } \\
\text { phase }\end{array}$ & 50 & Turns/phase \\
\hline Inertia & 0.0028 & Kg. $m^{2}$ \\
\hline Coefficient of Friction & 0.026 & N.m.s \\
\hline $\begin{array}{c}\text { Inductance } \\
\text { (Aligned Position) }\end{array}$ & 36 & $m H$ \\
\hline $\begin{array}{c}\text { Inductance (Unaligned } \\
\text { Position) }\end{array}$ & 3 & $m H$ \\
\hline Conducting Angle & 30 & degrees \\
\hline
\end{tabular}

Measurements of the flux linkage $(\lambda)$ were done for many rotor positions $(\theta)$, also considering different current values for each one of them. These measurements resulted in a large data bank of the function $\lambda(\theta, i)$. Using this data bank, a program for polynomial interpolation was constructing to represent the inductance of a phase as a function of its current and the instantaneous rotor position. Therefore, the matrix of states was evaluator considering the saturation effects.

The powers coming from an AC source, which, along with a rectifier bridge that, excite the SRG. As a result, it supplies the load through its windings. The excitation period of each phase begins when its switches are turning on and they start to conduct. At this moment the inductance is still increasing, the diodes are not conducting and the phase windings generate a positive back electromotive force. The generating period starts when the controlled switches are turning off, the phase current is deviated to the load through the diode and the phase windings generate a negative back electromotive force due to the change of $\frac{\partial L}{\partial \theta}$ sign. Fig. 3 shows the process described above. Load voltage obtained from equation (2).

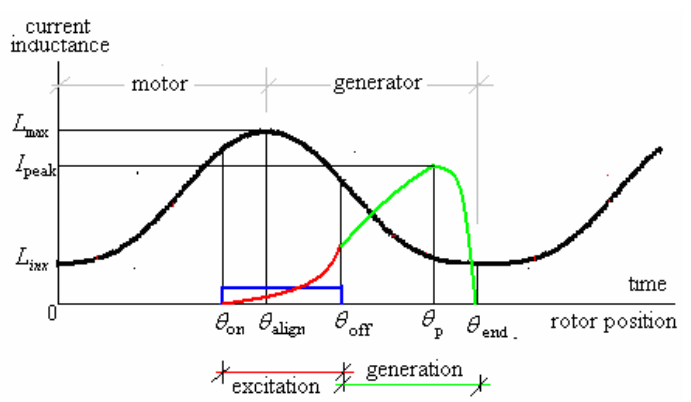

Fig. 3 - Excitation and generation periods.

The matrix of states above - equation (8) - was check using a computing program whose inputs are the phase voltages and the mechanical torque. The outputs are the phase currents, the angular speed and the rotor position. Each new set of values for the phase voltages and the torque was use to evaluate the next state. The program uses dynamic values that result from the relationship among the components of the converter circuit and from the relations among them and the AC source, the rectifier bridge, the machine and the load. Only the information of the rotor position is necessary to control the gate signals.

Fig. 4 shows that the measured values for the voltage over a winding match the results predicted by simulation.

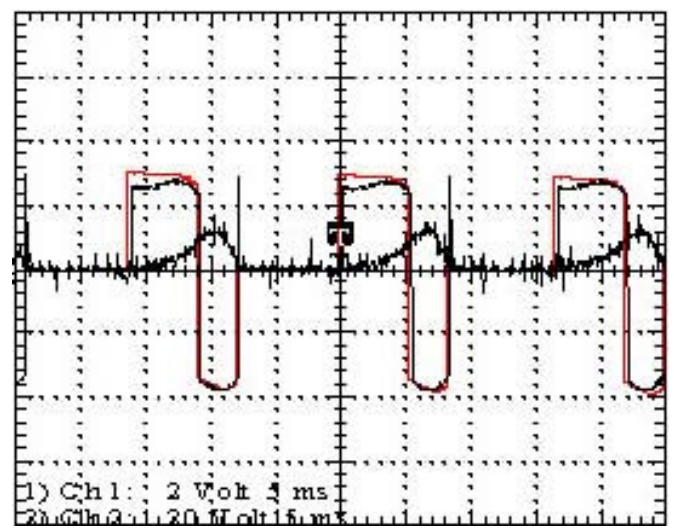

Fig. 4 - Voltage and current over a winding. Simulation and experimental results for the voltage. 


\section{Experimental Results}

The analysis of the lack of phase in Switched Reluctance Motors is known in some simulations [1], [2]. The prototype constructed for testing enables to test the effects of the lack of any phase in a Switched Reluctance Generator experimentally. This allows one to analyze the dependence or independence among the phases.

The experimental results have been achieving from the prototype already specified. The converter used was not the conventional half bridge one but that showed in Fig. 2.

The comparative data always were obtained from the phase A windings. The speed of the machine stood at $1155 \mathrm{rpm}$ all the time. The excitation voltage was always of $35.5 \mathrm{~V}$. The same resistive load remained in the output in all the tests conduced.

Fig. 5 shows excitation and the generated voltages in the phase when all the three phases were connect and activated. The excitation voltage was $35.5 \mathrm{~V}$ with a current of 10.6A. The load was feeding with $74.47 \mathrm{~V}$, $6.89 \mathrm{~A}$. Therefore, the SRG was generating a net power of $136.8 \mathrm{~W}$ and delivering it to the load.

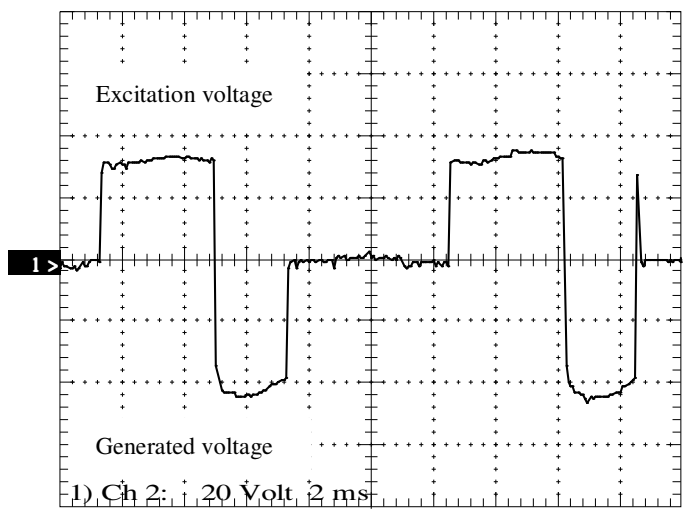

Fig. 5 - Excitation and generated voltage over a phase winding.

Dealing with resistive load the voltage and the current were in phase. The waveform of the current is showing in Fig. 6.

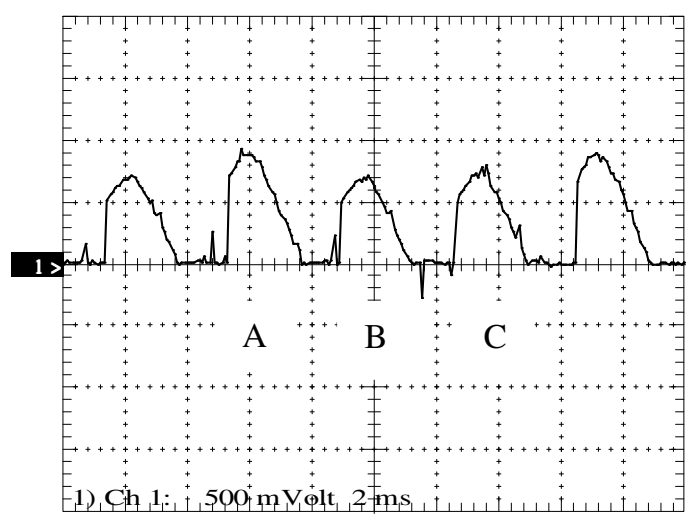

Fig. 6 - Current waveform when the SRG operates with its three phases.

In Fig. 7 it can be seen the excitation voltage and the generated voltage with the lack of the phase B. The excitation was of $35.5 \mathrm{~V}$ and $8.49 \mathrm{~A}$. The corresponding measurements over the load were $64.10 \mathrm{~V}$ and $5.94 \mathrm{~A}$ Thus, the net generated power delivered to the load was $79.36 \mathrm{~W}$. As waited this value is different from that found with all the three phases. However, with $33 \%$ off, $136.8 \mathrm{~W}$ still gives $91.19 \mathrm{~W}$ as result. This value is expressively greater than the $79.3 \mathrm{~W}$ found. This difference shows that there is a strong dependence among the phases of the SRG. When a phase is disconnected, the other two phases generate each one less power than they do when all they work together.

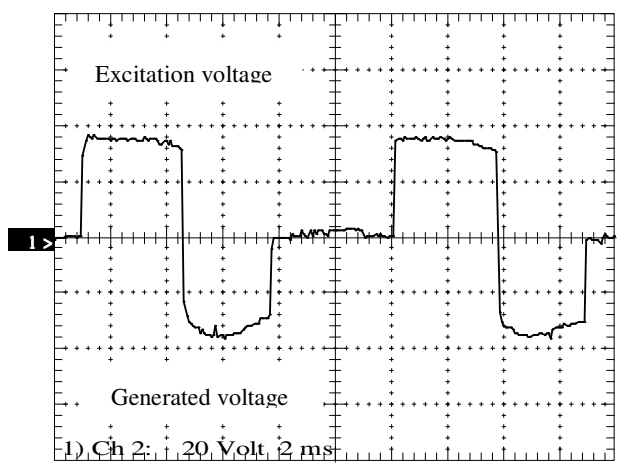

Fig. 7 - Excitation voltage and generated voltage with the lack of phase B.

Fig. 8 shows the waveform for the current in the two active phase windings.

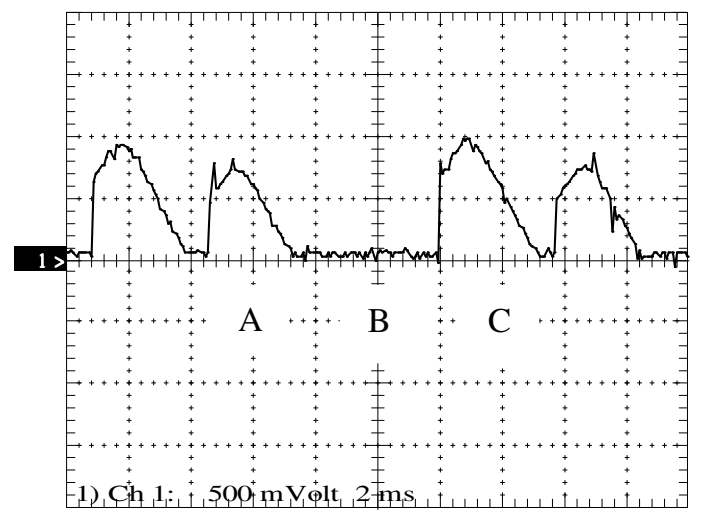

Fig. 8 - Waveform for the current in the two active phase's windings.

\section{Conclusions}

Many important works show the independence of the phases in a switched reluctance motor. This paper focuses this matter regarding for a SRG. It presents experimental results that showing that the phases presented a clear dependence considering the prototype and the converter used in testing. In fact, these results show a hard mutual influence among the three phases. Not only the waveforms but also the values change when just one phase is disconnected. This result claims for a deeper investigation. This investigation must consider the mutual inductance.

\section{References}

[1] Hussain, I., Radun, A., Nairus, J., "Fault Analysis and excitation requirements for Switched Reluctance 
Generators", IEEE Trnasactions on Energy Conversion, Volume 17, Issue 1, march 2002, pp. 67-72.

[2] Sawata, T., Kjaer, P. C., Cossar, C., Miller, T. J. E., Hayashi, Y., "Fault-Tolerant Operation of Single Phase SR Generators", IEEE Transactions on Industry Application, Volume 35, Issue 4, July-Aug 1999, pp. 774-781.

[3] Fleury, A., Andrade, D. A., Silva, F. S., Domingos, J. L., "Switched Reluctance Generators Behavior under Different Conditions”, ISIE'07 records, 2007.

[4] Sawata, T., "The Switched Reluctance Generator", Electronic Control of Switched Reluctance Machines, Edited by T. J. E. Miller, Newness Power Engineering Series, 2001, pp. 237-250. 